\title{
Pregnancy After Tubal Sterilization in a Woman Treated with Biologics for Severe Psoriasis
}

\author{
Charlée Nardin · Morgane Colas · Vincent Curie · Fabien Pelletier •
}

Eve Puzenat · François Aubin (D)

Received: November 15, 2017 / Published online: March 9, 2018

(c) The Author(s) 2018. This article is an open access publication

\section{ABSTRACT}

Little is known about whether immunosuppressed patients mount the immunological response necessary to ensure tubal occlusion. Theoretical concern for non-occlusion has limited the use of hysteroscopic sterilization in patients on immunosuppressive therapies. The effects of tumor necrosis factor-alpha (TNF- $\alpha$ ) blockers and interleukin (IL)-17 inhibitors on contraception and pregnancy for patients with psoriasis are poorly documented. We report a case of pregnancy that ended in miscarriage in a patient treated first with TNF- $\alpha$ and then with IL-17 inhibitors for severe psoriasis after tubal sterilization with micro-inserts. Our observation suggests that the efficacy of tubal sterilization by micro-inserts may be impaired by these two biologics and that the risk of miscarriage may be

Enhanced content To view enhanced content for this article go to https://doi.org/10.6084/m9.figshare. 5943694 .

C. Nardin $\cdot$ M. Colas $\cdot$ F. Pelletier $\cdot$ E. Puzenat F. Aubin ( $\square)$

Service de Dermatologie, Centre Hospitalier

Universitaire, Université de Franche Comté, Unité de recherche EA 3181, Besançon, France e-mail: francois.aubin@univ-fcomte.fr

V. Curie

Service de Gynécologie, Centre Hospitalier, Dole, France increased in women with psoriasis treated with secukinumab.

Keywords: Biologics; Pregnancy; Psoriasis; Sterilization

\section{INTRODUCTION}

Micro-inserts are a non-incisional permanent method of contraception. The micro-insert is a dynamically expanding micro-coil. When the micro-inserts are in place, body tissue grows in them and blocks the fallopian tubes, resulting in permanent contraception. The effects of both tumor necrosis factor-alpha (TNF- $\alpha$ ) blockers and interleukin-17 (IL17) inhibitors on contraception and pregnancy are poorly documented. We report a case of pregnancy that ended with miscarriage in a patient treated with these biologics for severe psoriasis after tubal sterilization with micro-inserts.

\section{CASE REPORT}

Informed consent was obtained from the patient for being included in the study.

A 45-year-old white female patient had suffered from cutaneous psoriasis since her adolescence. She had six children delivered vaginally and one miscarriage. At the age of 
43 years, she underwent hysteroscopic tubal sterilization with micro-inserts (Essure ${ }^{\circledR}$; Conceptus Inc., Bayer AG, Leverkusen, Germany). At age 40 years, she developed severe psoriasis involving $30 \%$ of the body surface area that had a major impact on her quality of life. The psoriasis had been successively treated with methotrexate, TNF inhibitors (etanercept, adalimumab, infliximab from age 40 to 44 years) and lastly secukinumab. After 3 months of treatment with secukinumab, she developed amenorrhea. Measurements of human chorionic gonadotropin levels and an ultrasound scan revealed interruption of an intra-uterine pregnancy at 6 weeks of gestation. She was treated by dilatation and curettage.

\section{DISCUSSION}

Contraception is recommended for women who are treated with biologics for psoriasis. Although a few cases of successful hysteroscopic sterilizations with micro-inserts in patients treated with steroids, mycophenolate mophetil and sirolimus have been reported, this method of contraception in immunosuppressed women is discouraged by the manufacturer [1]. Currently, the instructions for use included in each Essure ${ }^{\circledR}$ kit contain the following warning: "Patients undergoing immunosuppressive therapy are discouraged from undergoing the Essure ${ }^{\circledR}$ procedure because the immunosuppressant may lead to decreased tissue ingrowth" [2]. It should be noted that this sterilization implant was recently withdrawn from the non-USA market because of different adverse events, including chronic pain, perforation of the uterus and fallopian tubes. Our case report highlights that the efficacy of tubal sterilization with micro-inserts may be impaired by treatment with TNF inhibitors as well as IL17 inhibitors. Histologically, the micro-inserts produce an immediate foreign body inflammatory reaction at 2-3 weeks followed by fibrosis at between 8 and 30 weeks [3]. Because foreign body cells participate in the inflammatory response through the production of cytokines, including TNF- $\alpha$ and IL-17 [4], their inhibition could theoretically alter the foreign body reaction. Continuing to use another form of contraception during a 3-month period until bilateral tubal occlusion is documented by hysterosalpingogram or ultrasound is thus recommended in all immunosuppressed patients who undergo hysteroscopic sterilization [1].

Our case also suggests that TNF blockers and secukinumab may also be involved in the occurrence of spontaneous abortion. It has been hypothesized that anti-TNF treatment at the time of conception may be associated with an increased risk of spontaneous abortion [5]. However, the role of anti-TNF- $\alpha$ agents on spontaneous abortion in this case is unlikely since the patient had stopped taking anti-TNF- $\alpha$ agents for many months when she inadvertently became pregnant.

It should also be noted that the patient's profile fulfilled three risk factors for spontaneous abortion: she had had one spontaneous abortion, she was 45 years old and she was multiparous [6-8]. Thus, the possibility cannot be excluded that this spontaneous abortion fell into the rate of abortions (25\%) taking place in the general population [9].

It has been reported that patients suffering from psoriasis have an increased rate of pregnancy complications, such as spontaneous abortions, recurrent pregnancy losses, failure to conceive and preterm deliveries [10, 11], although reports on pregnancy outcomes in women with psoriasis are conflicting $[12,13]$. A recent review suggested that immune system deregulation in psoriasis likely leads to poorer outcomes in pregnancy [14].

Our case is the first report of pregnancy in a patient on secukinumab therapy. Regarding IL17-inhibitors, developmental toxicity studies in animals found that the administration of secukinumab during pregnancy in cynomolgus monkeys did not result in maternal toxicity, embryofetal toxicity or teratogenicity [15]. To date, controlled data in human pregnancy are not available. Thus, it is possible that IL-17 inhibitors are toxic to the human embryo even if toxicity studies in animals have not yet demonstrated it. A balance between $\mathrm{T}$ helper 1 (Th1), T helper 17 (Th17) and T helper 2 (Th2) signaling pathways is indeed required for implantation, development of the placenta and 
maintenance of pregnancy [16]. Thus, it could be hypothesized that IL-17 inhibitors may compromise the immunity of the fetus and neonate by dysregulation of the Th17 balance.

On the other hand, it is hypothesized that pro-inflammatory cytokines which are elevated in the sera and psoriatic skin have detrimental effects on the maternal placenta and could thus lead to adverse pregnancy outcomes. During pregnancy, the foreign fetal antigens challenge the maternal immune system, and Treg cells will dominate Th17 cells to guarantee fetal survival. An increased Th17/Treg ratio has been found in patients with pregnancy complications and autoimmune diseases [16]. These data suggest that human Th17 cells may play a major role in rejecting conceptus antigens and that restoration of Th17 balance with IL-17 inhibitors might protect these patients from pregnancy loss [16]. However, such data have not been obtained from psoriasis patients and therefore no conclusion can be drawn for this population.

\section{CONCLUSIONS}

In conclusion, the failure of sterilization and subsequent spontaneous abortion in a biologictreated patient is likely simply a coincidence. However, we cannot exclude the possible role played by the biologics. A better understanding of the role of the TNF- $\alpha$ and IL-17 signaling pathways in the inflammation reaction of the fallopian tubes induced by micro-inserts, in pregnancy maintenance and in miscarriage may help to define recommendations for contraception and pregnancy in women with severe psoriasis treated with TNF- $\alpha$ and IL-17 inhibitors.

\section{ACKNOWLEDGEMENTS}

Funding. No funding or sponsorship was received for this study or publication of this article. The article processing charges were funded by the authors.
Authorship. All named authors meet the International Committee of Medical Journal Editors (ICMJE) criteria for authorship for this manuscript, take responsibility for the integrity of the work as a whole, and have given final approval for the version to be published.

Medical Writing and/or Editorial Assistance. The authors would like to express their thanks to the whole team members involved in the management of the patient and Elisabeth Homassel for the preparation of the manuscript.

Disclousres. Charlée Nardin, Morgane Colas, Vincent Curie, Fabien Pelletier, Eve Puzenat and François Aubin have nothing to disclose.

Compliance with Ethics Guidelines. Informed consent was obtained from the patient for being included in the study.

Open Access. This article is distributed under the terms of the Creative Commons Attribution-NonCommercial 4.0 International License (http://creativecommons.org/licenses/ by-nc/4.0/), which permits any noncommercial use, distribution, and reproduction in any medium, provided you give appropriate credit to the original author(s) and the source, provide a link to the Creative Commons license, and indicate if changes were made.

\section{REFERENCES}

1. Ladanyi C, Field C, Tocce K. Hysteroscopic sterilization in immunocompromised patients who have intrauterine devices in place: two case reports. J Med Case Rep. 2015;9:239.

2. Bayer AG. Essure package insert. Bayer AG, Leverkusen, Germany. http://www.hcp.essure-us.com/.

3. Hurskainen R, Hovi S-L, Gissler M, et al. Hysteroscopic tubal sterilization: a systematic review of the Essure system. Fertil Steril. 2010;94:16-9.

4. Anderson J, Rodriguez A, Chang D. Foreign body reaction to biomaterials. Semin Immunol. 2008;20:86-100. 
5. Verstappen SMM, King Y, Watson KD, et al. AntiTNF therapies and pregnancy: outcome of 130 pregnancies in the British Society for Rheumatology Biologics Register. Ann Rheum Dis. 2011;70:823-6.

6. Kramer MS. The epidemiology of adverse pregnancy outcomes: an overview. J Nutr. 2003;133[5 Suppl 2]:1592S-6S.

7. Feodor Nilsson S, Andersen PK, Strandberg-Larsen K, Nybo Andersen A-M. Risk factors for miscarriage from a prevention perspective: a nationwide followup study. BJOG Int $\mathrm{J}$ Obstet Gynaecol. 2014;121:1375-84.

8. Maconochie N, Doyle P, Prior S, Simmons R. Risk factors for first trimester miscarriage-results from a UK-population-based case-control study. BJOG Int J Obstet Gynaecol. 2007;114:170-86.

9. Wilcox AJ, Weinberg CR, O'Connor JF, Baird DD, Schlatterer JP, Canfield RE, et al. Incidence of early loss of pregnancy. N Engl J Med. 1988;319:189-94.

10. Kwak-Kim JYH, Gilman-Sachs A, Kim CE. T helper 1 and 2 immune responses in relationship to pregnancy, nonpregnancy, recurrent spontaneous abortions and infertility of repeated implantation failures. Chem Immunol Allergy. 2005;88:64-79.
11. Ben-David G, Sheiner E, Hallak M, Levy A. Pregnancy outcome in women with psoriasis. J Reprod Med. 2008;53:183-7.

12. Cohen-Barak E, Nachum Z, Rozenman D, Ziv M. Pregnancy outcomes in women with moderate-tosevere psoriasis. J Eur Acad Dermatol Venereol. 2011;25:1041-7.

13. Seeger JD, Lanza LL, West WA, Fernandez C, Rivero E. Pregnancy and pregnancy outcome among women with inflammatory skin diseases. Dermatology. 2007;214:32-9.

14. Bobotsis $\mathrm{R}$, Gulliver WP, Monaghan $\mathrm{K}$, Lynde $\mathrm{C}$, Fleming $\mathrm{P}$. Psoriasis and adverse pregnancy outcomes: a systematic review of observational studies. Br J Dermatol. 2016;175:464-72.

15. European Medicines Agency (2004). Cosentyx. Available from: http://www.ema.europa.eu/docs/ en_GB/document_library/EPAR_Public_ assessment_report/human/003729/WC500183131. pdf.

16. Figueiredo AS, Schumacher A. The T helper type $17 /$ regulatory $\mathrm{T}$ cell paradigm in pregnancy. Immunology. 2016;148:13-21. 